\title{
LIFE CYCLE ASSESSMENT OF ARUNDO DONAX BIOMASS PRODUCTION IN A MEDITERRANEAN EXPERIMENTAL FIELD USING TREATED WASTEWATER
}

\author{
Claudia Arcidiacono, Simona M.C. Porto
}

\section{Introduction}

Biomass feedstocks for energy can be obtained from arable crops also grown for food and from dedicated crops, the 'energy crops', "that are bred or selected to produce biomass with specific traits that favour their use as an energy vector" [European Biofuels Technology Platform 2008].

In some areas of the Mediterranean basin, the environment, being characterised by high temperatures during summer and low water availability, affects the energy and cellulose production of biomass. In fact, previous research indicated that Arundo donax L. (giant reed), Miscanthus spp. and cardoon are among the most promising species [Mantineo 2009]. In particular, Arundo donax performed better than the other two crops in terms of yield, net energy yield and energy ratio [Angelini 2009].

Mantineo [2009] found that energy efficiency of Arundo donax proved considerably lower in the first three years of trial than that found by other Authors [Angelini 2005; Angelini 2007] because of the energy cost of irrigation, whereas it increased in the fourth and fifth year, where only the energy cost of harvest was applied. However, besides the energy efficiency of Arundo donax, also its environmental sustainability should be taken into account through methodologies which analyse the energy and environmental performance of the Arundo donax production system [Heller 2003].

Paper received 08.03.2011; accepted 27.07.2011

Claudia ARCIDIACONO, associate professor (corresponding author), carcidi@unict.it, tel.+39095 7147576, Department of Agri-Food and Environmental Systems Management - Section: Building and Land Engineering, University of Catania, via S. Sofia 100 - 95123 Catania (Italy). Simona M.C. PorTo, Phd, University of Catania, Department of Agri-Food and Environmental Systems Management - Section: Building and Land Engineering, University of Catania, via S. Sofia 100 - 95123 Catania (Italy). All authors of this research paper have equally participated in the planning, execution, and analysis of this study.
On this basis, in this paper Life Cycle Assessment (LCA) was applied to the biomass production of the Arundo donax crop grown in an experimental field and irrigated with urban wastewater. The study aimed to highlight possible weak points of the production process, in relation to raw material-and-energy fluxes through the system, and variability of Arundo donax productivity in a life cycle of 10 years.

\subsection{Literature review}

The basic principles of Life Cycle Assessment (LCA) were defined in USA and in Europe between the Sixties and the Seventies, and from the Eighties studies on LCA received a new stimulus on a worldwide scale with the aim to quantify the resources needed for goods production and for enhancement of production processes as well as for evaluating the related emissions to the environment.

The LCA of a product or a process is generally developed to highlight critical points of a production process in order to reduce consumption of energy, raw materials and emission/waste production as well as to evaluate the environmental or energy performance of a product/process in comparison to an analogous product/process and identify possible improvements to be done towards the achievement of environment sustainable development.

LCA is an objective analysis technique which, on the basis of quantifiable parameters and specific phases, makes it possible to direct policy actions inherent to environmental problems. The assessment concerns the whole life cycle ('from cradle to grave') and includes 'the extraction and the treatment of raw materials, the manufacturing process, the transport, the distribution, the use, the reuse, the recycling and the final disposal'. By analyzing LCA results, decisors could derive suggestions for strategic choices aiming at reducing environmental risks.

As a consequence of the considerable misuse of LCA studies, which proliferated to assess product or processes for marketing purpose [Klöpffer 2006], in 1990 the Society of Environmental Toxicology and Chemistry (SETAC) began an extensive activity aimed 
at reaching an agreement at the international level about the definition of guidelines and methodological recommendations about LCA. This activity led to the definition of the SETAC Code of practice [Russell 2005]. The standardization process continued then with the drafting of ISO standards. At present, in fact, the current standards ISO 14040:2006 [UNI 2006a] and ISO 14044:2006 [UNI 2006b] derive from ISO 14040:1997 [UNI 1997], and from ISO 14041:1998 [UNI 1998], ISO 14042:2000 [UNI 2000a] and ISO 14043:2000 [UNI 2000b], respectively.

Within production processes of energy crops, LCA makes it possible to evaluate the overall environmental burden of the biomass supply chain, i.e. from the biomass production to its combustion in boiler. In this regard, several studies based on LCA have been carried out with the aim to assess environmental impacts of crop energy production processes by means of holistic and quantitative approaches. In detail, in 1998 the Dutch centre for Agriculture and Environment (CLM) developed a systematic methodology to assess the ecological and socio-economic sustainability of ten biomass crops. The results were used to outline the perspectives for a large scale production with regard to medium and long term land availability. CML found that the use of crops for the generation of energy produces a low impact compared to the use of crops for transport fuels [Hanegraff 1998].

Jungmeier and Spitzer [2001] found that greenhouse gas emission was reduced significantly by replacing fossil energy systems (oil, natural gas and coal) with some bioenergy systems from agriculture.

Lewandowski and Heinz [2003] analysed the influence of the harvesting time on environmental impacts of energy production. They concluded that an early harvest of miscanthus maximises energy yield and finite primary energy savings per hectare.

Heller [2003] analysed environmental performance of willow biomass crop production systems. Under specific conditions - reasonable biomass transportation distance and efficiency of the energy conversion systems - they demonstrated that generating electricity from willow biomass crops is sustainable from an energy balance perspective and contribute to obtain additional environmental benefits.

Iriarte [2010] carried out a research in Chile with the aim to compare environmental impacts, and energy and water demand of two types of energy crops rapeseed (Brassica napus L.) and sunflower (Helianthus annuus L.) - considered as potential oleaginous crops for first-generation biodiesel production. They elaborated a cradle-to-farm gate Life Cycle Assessment and found that rapeseed production has a better environmental performance in 9 out of the 11 impact categories evaluated and lower water consumption.

Muñoz [2010] assessed the life cycle of Nicotiana tabacum cultivated in a Mediterranean greenhouse. During the experiment, different types of water sources - groundwater, treated wastewater and desali- nated seawater - were used to irrigate different parcels of the analysed biomass. The authors found that using desalinated water leads to higher environmental impacts in several impact categories, including global warming, energy use, soil quality, and aquatic ecotoxicity.

Recchia [2010] applied LCA to validate some environmental indicators used in a method based on a multicriteria analysis aimed at evaluating the energetic reuse of riparian vegetation. The method was applied to two hydrological districts of Tuscany (Italy) characterised by different vegetation typologies and densities. The authors found that the most interesting bio-energy chains are those requiring a limited forestry mechanisation, short transport distances and medium sized plants.

\section{Material and methods}

\subsection{ISO Standards}

The ISO 14040:2006 standard describes the general criteria of the methodology and identifies its main phases: goal and scope definition, inventory analysis, life cycle impact assessment, life cycle interpretation. The LCA procedure is iterative and interactive, i.e. requirements, objectives and/or the application field can be modified after data collection [UNI 2006a]. The ISO 14044 standard analyzes the phases of LCA identified by ISO 14040. In detail, in the first two phases it is necessary to: describe the system which is the object of the study, and list data categories to be analyzed; define the characteristics of product/process performance, quantifying them by defining the functional unit which all input and output data must be referred to; identify and quantify the input and output fluxes of the system, structuring this activity in data collection, a computation process and interpretation of results. In the third phase of LCA the results of the inventory analysis are elaborated to obtain information about the potential damages associated to human health, resource depletion, and environmental degradation. Finally, the standards allow data interpretation to be carried out also by comparing different products with the aim to find out the best one from the point of view of environmental sustainability.

\subsection{Description of the experimental field}

The experimental field is sited in the Municipality of San Michele di Ganzaria, in the province of Catania (Italy), at an altitude of 490 meters above the mean sea level. Arundo donax is grown in two parcels of $486.5 \mathrm{~m}^{2}(17.5 \mathrm{~m} \times 27.8 \mathrm{~m})$ within the experimental field. A micro-irrigation system which distributes urban wastewater, stored in a reservoir, after a constructed wetland is used. The water distribution system is composed of the storage reservoir of about 40 $\mathrm{m}^{3}$ and a micro-irrigation plant constituted by the fol- 
lowing components: a vertical multi-stage pump (2.2 $\mathrm{kWh}$ ), a disk filter, PE pipelines having different diameters (16 $\mathrm{mm}$ for dripping pipes and $40 \mathrm{~mm}$ for water main distribution), T-shaped joints, ring joints, closing and calibration valves, volumetric meters, a manometer and accessories. All these elements were taken into consideration in the LCA. In detail, all the works needed to build the reservoir were considered (excavation, soil compaction, waterproofing, etc.), and production processes of the micro-irrigation plant components were analyzed. Some of them are considered to be replaced during a life cycle of 10 years. In detail, due to mechanical harvesting of the biomass, 16-mm pipes are considered to be substituted every year, whereas for $40-\mathrm{mm}$ pipes this is done every 5 years. The irrigation volumes actually distributed in the field are monitored by volumetric meters placed near the distribution point of each sector and the irrigation need is computed by using a microclimatic station composed of dataloggers and sensors for the estimation of plant evapotraspiration. Wastewater is analyzed to determine the chemical-physical properties (BOD5, COD, SST, Nitrogen in different forms and total Phosporous content) [Barbera 2009]. The Arundo donax plants transplanted in the experimental field were purchased from a nursery which utilizes the micropropagation technique. Therefore in the LCA the three main subprocesses which compose the production process of Arundo donax seedlings were considered: micropropagation, subcultivation and greenhouse nursery growing.

\subsection{LCA analytical methods and databases}

To facilitate the application of ISO standards and support LCA studies, several softwares have been developed (SimaPro, GaBi, EcoLab, etc.), based on different impact assessment methods (EcoIndicator, EDIP, etc.), which use or are integrated with databases of products and processes (Ecoinvent, Idemat 2001 , etc.). These databases include a range of official data sets from industry associations, research centers, etc., in the different countries, and are periodically updated. Recently, at the European level, work on databases is in the field of data harmonization, and coordination of software and database developers to provide adequate import/export interfaces.

In this study, collected data were elaborated by using the software Simapro 7.1 with the Ecoinvent 99 database which assembles all the most requested data on materials, production processes, energy generation, product disposal, etc. The computation method used for the analyses carried out in this study was Eco-indicator 99. This method is based on a damage-oriented approach. In detail, three typologies of environmental damage are considered (human health: $\mathrm{HH}$, ecosystem quality: $\mathrm{EQ}$, resources: $\mathrm{R}$ ) which in turn are subdivided in 11 impact sub-categories [Prè Consultants 2008a]. The Eco-indicator 99 method refers to parameters at the European level, and damages are normalized with reference to the damage caused to a European citizen in a year. For each scenario an index, named 'single score' is computed and applied to the three damage categories and to the whole process. The value of the single score increases with damage. In this study the hierarchic weight defined within Eco-indicator 99 was applied [Prè Consultants 2008b]. The Hierarchic method considers all the damaging substances in a medium-term perspective, with a weight incidence, associated to the damage categories, distributed as follows: HH $30 \%$; EQ $50 \%$; R $20 \%$.

\subsection{Application of the LCA methodology to the case study}

According to UNI 14040, the goal and the scope of the LCA were firstly defined. In detail, the objective is the evaluation of the incidence of the different stages of the process on the overall environmental burden due to Arundo donax production. This evaluation was carried out with the aim to identify possible weak points in the process and acquire a wider knowledge suitable to suggest, together with further investigation and research, different scenarios of biomass production with a low environmental impact. The scope of the analysis was referred to the functional unit of $1 \mathrm{t}$ of biomass of fresh matter. The choice of this functional unit, instead of the unit of energy (1 MJ) comes from data availability. In fact, in this study productivity data were taken from literature. Therefore, if also literature data would have been taken for energy characteristics, uncertainties related both to energy and productivity would have caused a higher approximation of the results.

Data regarding Arundo donax biomass production in Sicily is about $10 \mathrm{t} / \mathrm{ha}$ of dry matter (D.M.) for the first year [Cosentino 2006; Barbera 2009; Final report PRIN 2007], while for the second year it varies between 22 t/ha D.M. [Cosentino 2006] and 38.9 t/ha D.M. [Final report PRIN 2007]. Literature shows that production increases in the next years reaching values higher than 20 t/ha D.M. [Angelini 2005; Angelini 2009]. Therefore, in the analyses a minimum value of field productivity equal to $15 \mathrm{t} / \mathrm{ha}$ of fresh matter (F.M.) was considered for the first year whereas a productivity of $45 \mathrm{t} / \mathrm{ha}$ F.M. for the next years.

The production stages and the related subprocesses used to describe Arundo donax production are shown in Figure 1 by using a block diagram [Bidini 2006]. In this study the environmental burden associated to the whole biomass production process was evaluated considering the specific contribution of the different stages. Moreover, the saved resources were evaluated in terms of avoided environmental burden due to the use of wastewater instead of conventional resources and fertilizers. Thanks to soil clay nature and stratigraphy in the area under study, it is possible to neglect the percolation of the part of wastewater nutrients incompletely absorbed by the crop. The wastewater 
treatments developed before the storage reservoir was considered outside system boundaries as these treatments are carried out independently from the subsequent use of the wastewater yet to comply with the regulations in force concerning the disposal of wastewaters. To generalize the results, also the combustion in the boiler was considered outside the system, because the emissions associated to the combustion process are affected by the type of boiler used.

In the proposed analyses the environmental burden related to the first year of biomass cultivation (first scenario) and that associated to a production cycle of 10 years (second scenario) were considered with the aim to evaluate the reduction over time of the burden due to the initial agronomic practices and to find out the incidence of some yearly operations on the overall burden. Furthermore, other two scenarios were considered with the aim to highlight production-stage burden variation due to an increase of crop productivity. In detail, a third scenario was carried out considering only the first year of cultivation fixing a maximum value of production equal to $65 \mathrm{t} / \mathrm{ha}$ F.M., whereas a fourth scenario was built by fixing a maximum value of production equal to $25 \mathrm{t} / \mathrm{ha}$ F.M. for the second year until the end of the 10-year life cycle.

To identify the production stages which determine the highest impacts, the incidence of the following production-stage subprocesses were considered for each scenario:

- Seedling production: micropropagation, sub-cultivation and greenhouse nursery growing (included the transport from the nursery to the field, which was considered to be carried out at a regional scale, i.e. a distance of $250 \mathrm{~km}$ ).

- Agronomic practices: soil preparation, seedling transplanting in the field, irrigation with treated urban wastewater, harvesting.

- Irrigation: storage reservoir building, irrigationplant component supply (PE pipes, pumps, and pipe fittings).

- Transport to the boiler: transport activity from field site to boiler was considered to be carried out at a regional scale, as for seedling production subprocess.

In this work the disposal of materials used in each subprocess was considered.

According to the second phase of LCA in the standards, data collection was carried out by identifying the fluxes of raw materials and energy for each subprocess within the system boundary.

\subsection{LCA result uncertainty}

In this research the Monte Carlo (MC) analysis was used in order to determine data uncertainties. In detail, in the Ecoinvent 99 database the Pedigree Matrix is used to estimate data standard deviations for lognormal distributions. The Pedigree Matrix includes quality indicators (reliability, completeness, temporal correlation, geographical correlation, further technological correlation, sample size) which allow the qualitative assessment of data uncertainties. Specific cal-

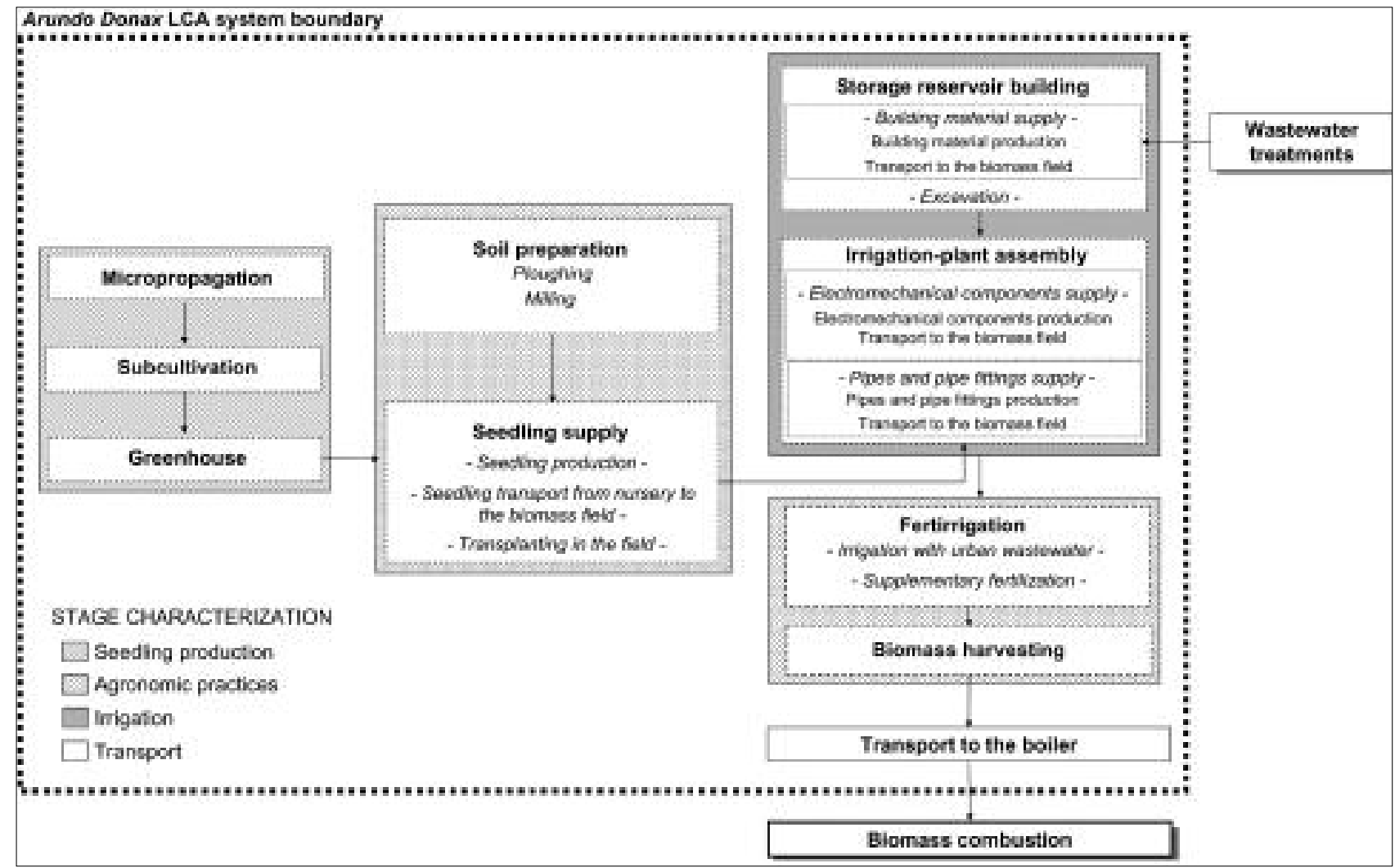

Fig. 1 - Production stages and related sub-processes used to describe Arundo donax production. 
culations of the Pedigree Matrix must be carried out for production-stage subprocesses when they are not included in the Ecoinvent database.

In this study lognormal distributions for 'Storage reservoir building' processes were incorporated into the spreadsheet cells and the MC simulation was carried out by specifying the following parameters: Ecoindicator $99(\mathrm{H})$ as impact assessment method used; 10,000 runs in order to have a sufficient high number of trials. The MC analysis was carried out by using the software Simapro 7.1 with Ecoinvent 99.

\section{Results}

The single scores of the 10-year life cycles related to the minimum and maximum productivity results equal to $604 \mathrm{Pt}$ and $395 \mathrm{Pt}$, respectively. The values, expressed in percentage, of the rate between the single score of the considered subprocess and that of the whole process in the considered scenarios are reported in Tables 1-2. In these tables, on the basis of the Ecoindicator 99 method, burden values were subdivided into damage categories (Human Health, Ecosystem Quality, Resources). In detail, each production stage was subdivided into subprocesses having different environmental impacts according to the considered scenario.

In all the scenarios analyzed, it resulted that seedling production and the irrigation stage determined, over the whole process, the highest impacts in percentage, with values ranging between $43.98 \%$ $\div 68.08 \%$ and $27.60 \% \div 37.65 \%$, respectively. In detail, the percentages related to damage categories show that the highest values were reached by the resource damage category $(34.28 \div 53.07 \%)$ within 'seedling production' stage, followed by the human health damage category $(21.24 \div 29.81 \%)$ within the 'irrigation' stage. The EQ damage category, instead, is always characterized by lower values ranging between $2.35 \%$ and $0.08 \%$ within the whole process.

The comparison between the results obtained for the first year of cultivation and those obtained in the 10-year life cycle shows that the raw materials (saved conventional resources and fertilizers, and pipes), incoming energy into the system (electricity needed to pump functioning), and yearly activities (harvesting and transport of the biomass), which are carried out during the whole period of plant growth, determine higher impacts (in percentage) in the 10-year life cycle than in the first year of cultivation in all scenarios (Tab. 1-2). For instance, in maximum production scenarios, the construction of the storage reservoir decrease in incidence from $13.1 \%$ to $8.5 \%$ when the considered life cycle goes from 1 year to 10 years, whereas the substitution of the 16-mm pipes every year produces an impact increase from $8.3 \%$ in the 1 year cycle to $24.2 \%$ in the 10 -year cycle, respectively. This result shows that a different irrigation system should be designed to reduce the environmental im- pact of biomass production.

As regards the seedling production stage, in the maximum productivity scenario related to the first year of cultivation (Tab. 2), for instance, micropropagation, subcultivation and seedling growth under greenhouse have incidences over the total impact of $19.21 \%, 22.51 \%$ and $25.83 \%$, respectively. Therefore, under the hypothesis of using rhizomes of spontaneous plants the overall impact would reduce by $41.72 \%$. With reference to the high contribution which micropropagation and subcultivation confer to the whole environmental burden, the choice of micropropagated plants is acceptable if a productivity increase is attained in comparison to the use of plants rooted under greenhouse or rhizomes of spontaneous plants. Furthermore, by highlighting a high sensitivity of the single score to crop productivity, the results show that crop productivity constitutes a crucial parameter to correctly determine the process environmental burden, as analyzed by other Authors [Lewandowski 2003]. In this regard, further improvements could be obtained by defining a more appropriate Arundo donax yield curve through long-term experimental trials.

The agronomic practice stage affects to a minor extent the overall burden and, therefore, it can be regarded as a less significant stage in the assessment of the biomass production process and in the research of possible modification of the process. Greater attention must be given to this stage when considering a wider field for a large-scale biomass production, since it would require a suitable mechanisation [Recchia 2010].

\subsection{Uncertainty analysis}

In Figure 2 the results achieved from the uncertainty analysis carried out for 10-year life cycles in the case of the minimum value of Arundo donax field productivity are reported as bar charts and probability distributions of the damage categories. Table 3 summarises the following statistical parameters regarding the $\mathrm{MC}$ analysis computed for the $95 \%$ confidence interval: the average score of all results (Mean); the middle value obtained by sorting the results of all calculations (Median); the ratio between the standard deviation and the mean (Coefficient of variability); limits of the $95 \%$ confidence interval; the ratio between the standard deviation and the square root of the sample size (Standard error of the Mean).

From this MC analysis it came out that data uncertainties for the damage categories $\mathrm{HH}$ and $\mathrm{R}$ are relatively low, whereas the damage category EQ showed a higher value of uncertainty (Fig. 2). Similar results were obtained in other studies [Scipioni 2009], where EQ is recognized to be the most affected category by uncertainty on input data.

The use of standard deviations values for the lognormal distributions of the 'Storage reservoir building' processes, computed by using the Pedigree Matrix, improved the statistical parameters related to the damage 


\begin{tabular}{|c|c|c|c|c|c|c|c|c|c|c|c|c|c|c|c|c|c|c|c|c|c|c|c|c|}
\hline & \multicolumn{6}{|c|}{ SEEDUNG PRODUCTON } & \multicolumn{8}{|c|}{ AGAONCWOC PRAC nices } & \multicolumn{8}{|c|}{ ARFGGATON } & \multirow{2}{*}{\multicolumn{2}{|c|}{$\begin{array}{l}\text { TRANSPORT } \\
\text { TO THE BOLES }\end{array}$}} \\
\hline & \multicolumn{2}{|c|}{ Wiesprosogention } & \multicolumn{2}{|c|}{ scosutivision } & \multicolumn{2}{|c|}{ aneethosat } & \multicolumn{2}{|c|}{ Sost } & \multicolumn{2}{|c|}{ 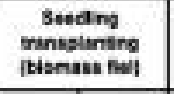 } & \multicolumn{2}{|c|}{ 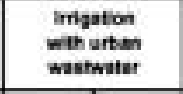 } & \multicolumn{2}{|c|}{ Haveresens } & \multicolumn{2}{|c|}{ 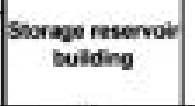 } & \multicolumn{2}{|c|}{ 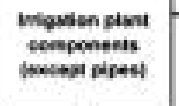 } & \multicolumn{2}{|c|}{40} & \multicolumn{2}{|c|}{$15 \mathrm{~mm}$} & & \\
\hline DAMUME CATEOORY & $\begin{array}{l}\text { Art } \\
\text { mat }\end{array}$ & 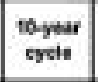 & $\begin{array}{l}\mathrm{Fin} \\
y=0\end{array}$ & 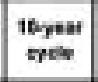 & $\begin{array}{l}\text { mox } \\
\text { mor }\end{array}$ & $\begin{array}{l}\text { Doyou } \\
\text { yocte }\end{array}$ & $\begin{array}{l}\text { Fist } \\
\text { now }\end{array}$ & 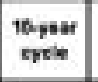 & $\begin{array}{l}\mathrm{Fin} \\
\mathrm{mon}\end{array}$ & $\left.\right|_{\substack{n \\
\text { nate }}}$ & $\begin{array}{l}\text { Fint } \\
\text { mox }\end{array}$ & \begin{tabular}{|c|}
$\begin{array}{c}\text { povest } \\
\text { getor }\end{array}$ \\
\end{tabular} & Fest & in:mets & $\begin{array}{l}\text { man } \\
\text { yen }\end{array}$ & 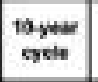 & $\begin{array}{l}\text { Fus } \\
\text { you }\end{array}$ & 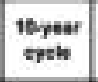 & Fins & 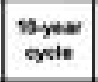 & $\begin{array}{l}\text { Fint } \\
\text { yeur }\end{array}$ & 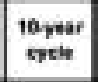 & $\begin{array}{ll}\mathrm{Fun} \\
\text { ser }\end{array}$ & 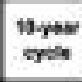 \\
\hline & 3.776 & 3,100 & 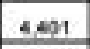 & 20 & 9 & 2.8 & 0,417 & o.0.03 & 0.20 & 0,31 & 0,404 & 1,336 & 0.097 & 0,000 & 1,040 & \begin{tabular}{|l|l|l|l|l|} 
\\
\end{tabular} & บT11 & $1 \mathrm{~ms}$ & 0.197 & \begin{tabular}{|l|} 
anes \\
\end{tabular} & 1,441 & 4.091 & 0.299 & 2.119 \\
\hline Ecospten Guatity $(x)$ & 8,700 & $0,0,5$ & 0,790 & 0.497 & 0.442 & 0.900 & 0.024 & a.0ir & 0.024 & 0.091 & 0,000 & 0,198 & 0.004 & 0.011 & 0.700 & 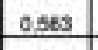 & asse & 0.004 & 0.014 & \begin{tabular}{|l|l|}
0.13 \\
\end{tabular} & 0,198 & 0.295 & 0 ans & 0.554 \\
\hline Resourcens (s) & 14 and & 12319 & 10 ant & 10,49 & 20.5อ & 14531 & 0,530 & 0.94 & 0.20 & ozan & 1,306 & 3651 & 0000 & 0,054 & 10 ma & $7 n 00$ & $213: 4$ & 1075 & 0,000 & on: & $6 A M$ & 1094 & om & 301 \\
\hline & 19361 & 18.53 & 22,687 & 13,4ta & 28.036 & 18342 & 0.332 & 0.234 & 0,737 & 0.519 & $1, m$ & S,914 & 0.090 & 0,085 & 13243 & \begin{tabular}{|l|l|}
9329 \\
\end{tabular} & 5022 & 3,598 & 1,180 & 1,850 & 8,410 & 2369 & 1.212 & 8,395 \\
\hline
\end{tabular}

TABLE 1 - First and second scenarios of Arundo donax LCA.

\begin{tabular}{|c|c|c|c|c|c|c|c|c|c|c|c|c|c|c|c|c|c|c|c|c|c|c|c|c|}
\hline & \multirow{2}{*}{\multicolumn{6}{|c|}{ SEEDUNG PROOUCNOH }} & \multirow{2}{*}{\multicolumn{8}{|c|}{ AORONCWOC PRAC TCES }} & \multicolumn{8}{|c|}{ IFPIOATON } & \multirow{3}{*}{\multicolumn{2}{|c|}{$\begin{array}{l}\text { TRANSPORT } \\
\text { TO THE BOLLER }\end{array}$}} \\
\hline & & & & & & & & & & & & & & & \multirow{2}{*}{\multicolumn{2}{|c|}{ 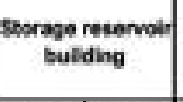 }} & \multirow{2}{*}{\multicolumn{2}{|c|}{ 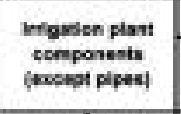 }} & & Pip & & & & \\
\hline & \multicolumn{2}{|c|}{ Niesprosospation } & \multicolumn{2}{|c|}{ Subsertersson } & \multicolumn{2}{|c|}{ Gesernous: } & \multicolumn{2}{|c|}{$\begin{array}{c}\text { Sod } \\
\text { proparoten }\end{array}$} & \multicolumn{2}{|c|}{ 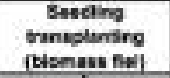 } & \multicolumn{2}{|c|}{ 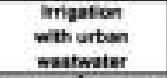 } & \multicolumn{2}{|c|}{ Herresting } & & & & & \multicolumn{2}{|c|}{ simm } & \multicolumn{2}{|c|}{$16 \%$} & & \\
\hline DAMAOE CATEGOQRY & $\begin{array}{l}\text { mint } \\
\text { max }\end{array}$ & $\begin{array}{l}10 y-200 \\
\text { cycte }\end{array}$ & $\begin{array}{l}\text { Mint } \\
\text { your }\end{array}$ & 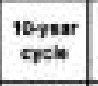 & $\operatorname{mox}_{n}$ & 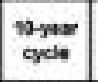 & $\underset{\substack{\text { nowt } \\
\text { you }}}{ }$ & $\begin{array}{c}\text { 1aperar } \\
\text { cothe }\end{array}$ & nom & 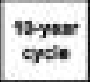 & $\begin{array}{l}\text { nint } \\
\text { nex }\end{array}$ & $\begin{array}{l}\text { 10year } \\
\text { cycter }\end{array}$ & 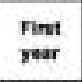 & 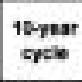 & $\begin{array}{l}m= \\
m \\
m\end{array}$ & 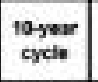 & $\begin{array}{c}\text { nint } \\
\text { nout }\end{array}$ & 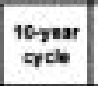 & $\operatorname{mos}_{\operatorname{mat}}$ & \begin{tabular}{|c|} 
mover \\
grete \\
\end{tabular} & $\sum_{\text {now }}$ & 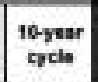 & nom $_{\text {nour }}$ & never \\
\hline Puman He & 3.746 & 2439 & 43956 & 2843 & 4.460 & 2.9 .8 & 0.117 & 0,075 & 0.825 & 0.212 & $0,40 t$ & 1,184 & 0,037 & 0.021 & 1,850 & 1,061 & 1677 & 1105 & 0.95 & 0.176 & 1,430 & 4,554 & 0.495 & 3.224 \\
\hline 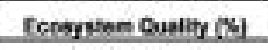 & 0089 & 2455 & 0793 & $\cos 2$ & ans & OMA4 & 0024 & 0.028 & 0,03 & 0,000 & 0009 & 0200 & 0024 & 0.011 & 0.782 & 0316 & ass & 0.300 & 0.44 & 9.933 & 0.194 & 0391 & 0.138 & OM7 \\
\hline Fencercess (S) & to $\mathrm{TES}$ & 9813 & $17 \times 7$ & 11,206 & 20.52 & 13371 & 0.199 & 0.123 & 0.639 & 0.296 & 1296 & 3,765 & 0.048 & 0.005 & 10744 & $6.9 \pi 7$ & $2.78+$ & 1811 & a.991 & Q.M90 & 6.999 & 18794 & 1,778 & $\mathrm{BPT}$ \\
\hline & 19706 & 12.597 & 22.505 & 4.8sa & 23927 & 15.918 & 9329 & 0.314 & 0,51 & 0.476 & 1,765 & 5,179 & 0.030 & 0.097 & $11,1 \mathrm{y}$ & | & 493 & 324 & 1,141 & 1,929 & 0.343 & 24,29 & 2.003 & 10.04 \\
\hline
\end{tabular}

TABLE $\quad 2$ - Third and fourth scenarios of Arundo donax LCA. 

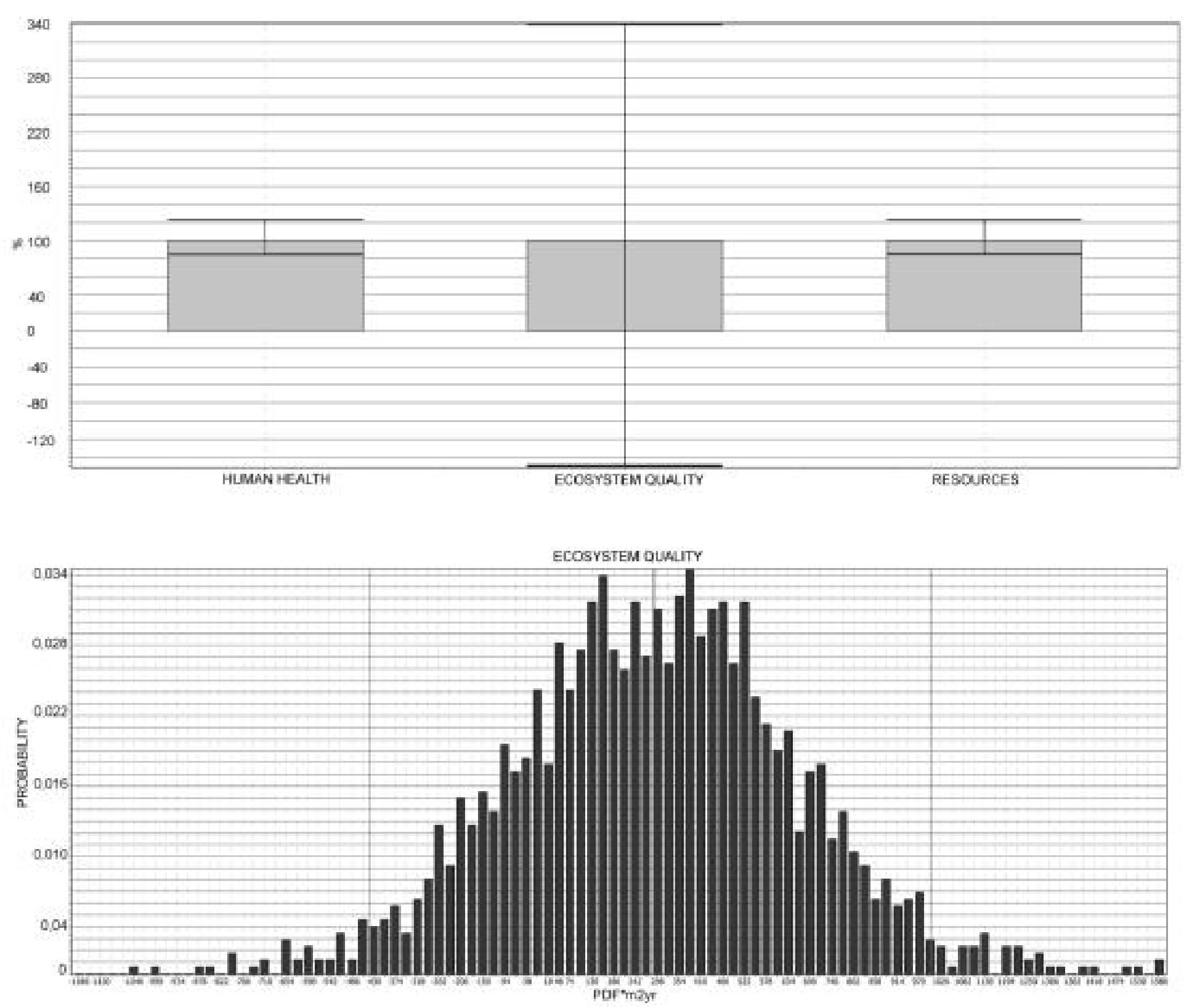

Fig. 2 - Graphical representation of the results obtained from the Monte Carlo analysis carried out for 10-year life cycles in the case of minimum value of Arundo donax field productivity: bar charts and distributions relative to the damage categories Human Health, Ecosystem Quality, and Resources. 

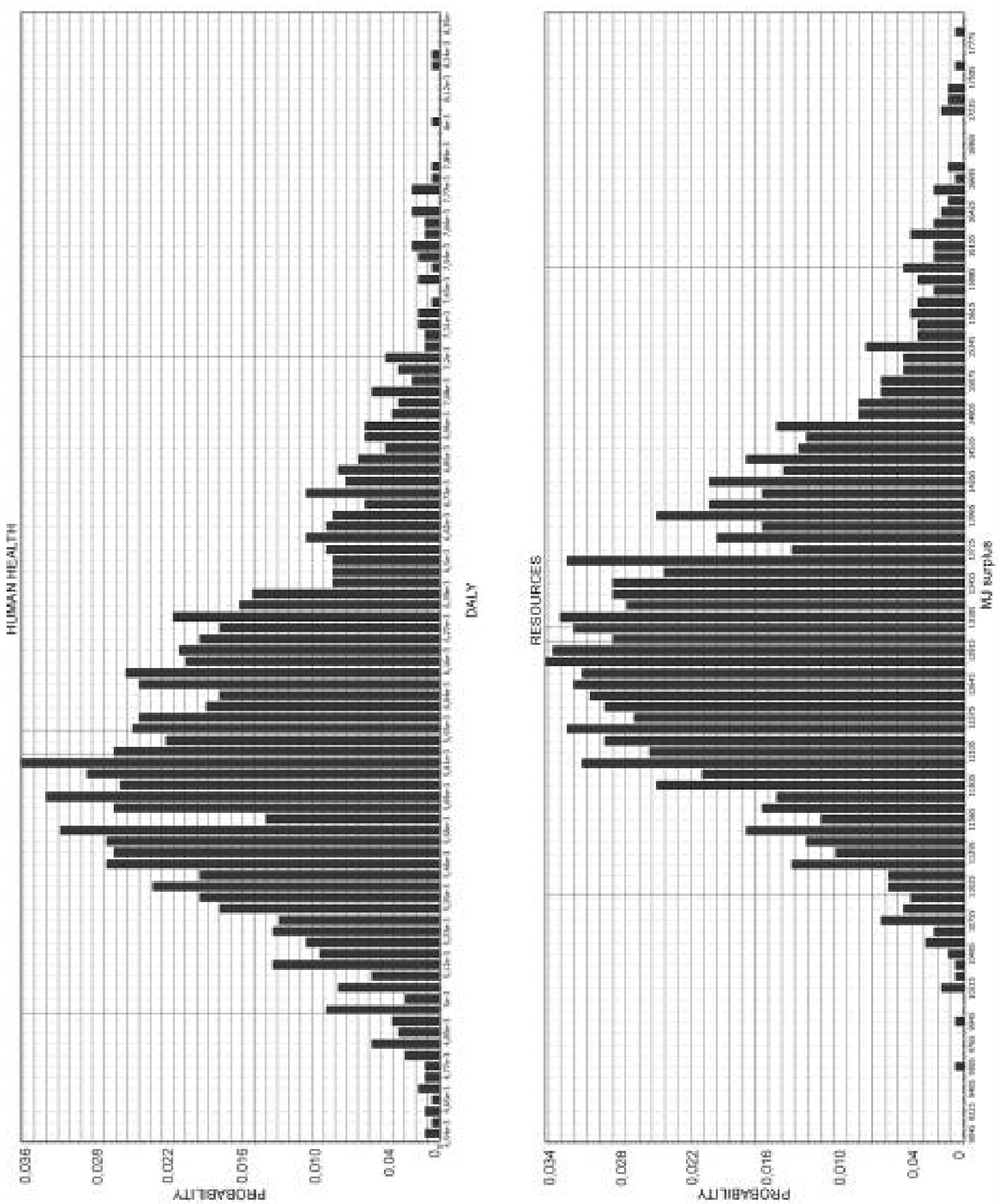

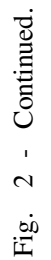




\begin{tabular}{|c|c|c|c|c|c|c|c|c|}
\hline Damage category & Unit & Mean & Median & $\begin{array}{c}\text { Standard } \\
\text { deviation }\end{array}$ & $\begin{array}{c}\text { Coefficient } \\
\text { of } \\
\text { variabilty }\end{array}$ & $\mathbf{2 . 5 \%}$ & $\mathbf{9 7 . 5 \%}$ & $\begin{array}{c}\text { Standard } \\
\text { error } \\
\text { of mean }\end{array}$ \\
\hline Resources & MJ surplus & 13100 & 13000 & 1250 & $9,52 \%$ & 11000 & 16000 & 0.00228 \\
\hline Human Health & DALY & 0.00592 & 0.00584 & 0.000577 & $9,75 \%$ & 0.00495 & 0.0072 & 0.00234 \\
\hline Ecosystem Quality & PDF_m2yr & 287 & 293 & 367 & $128 \%$ & -439 & 999 & 0.0307 \\
\hline
\end{tabular}

TABLE 3 - Statistical parameters of the Monte Carlo analysis (Confidence interval: 95\%).

categories in comparison to the results of the MC analysis performed without using data uncertainty.

\section{Conclusions}

The LCA of the production process carried out in this study, regarding biomass for energy purposes irrigated with wastewater, made it possible to identify the most significant stages affecting the environmental assessment. The results showed that the production of Arundo donax seedlings and the irrigation plant contributed most of all to the overall environmental burden. From these analyses suggestions regarding modification of some subprocesses, also in dependence on crop productivity scenarios, were proposed.

Further research would concern the analysis of a large-scale production process and the comparison between the production processes of different biomass carried out in the experimental fields belonging to the research project. As this study highlighted a high sensitivity of the biomass production process assessment to crop productivity, further investigation could be based on experimental results regarding the Arundo donax yield curve.

\section{Acknowledgements}

This research was financed by MIUR within the PRIN 2007 project on "Production and energy transformation of herbaceous biomasses irrigated with wastewater".

\section{References}

Angelini L.G., Ceccarini L., Bonari E., Biomass yield and energy balance of giant reed (Arundo donax L.) cropped in central Italy as related to different management practices. Europ. J. Agronomy, 2005, 22, 375-389.

Angelini L.G., Ceccarini L., Nassi o di Nasso N., Bonari E., Differences in biomass yield, chemical characteristics and energy balance between two Giant reed (Arundo donax L.) genotypes. Proceedings of 15th European Biomass Conference, Berlin, May 7-11, 2007, pp. 607-612.

Angelini L.G., Ceccarini L., Nassi o Di Nasso N., Bonari E. Comparison of Arundo donax L. and Miscanthus giganteus in a long-term field experiment in Central Italy:
Analysis of productive characteristics and energy balance. Biomass and bioenergy, 2009, 33, 635-643.

Barbera A.C., Milani M., Molari G., Toscano A., Villani G., Zema D.A., Zimbone S.M., Produzione e trasformazione a fini energetici di biomasse erbacee irrigate con acque reflue. Proceedings of the IX National Conference of the Italian Association of Agricultural Engineering, Ischia Porto, 12-16 September 2009.

Bidini G., Cotana F., Buratti C., Fantozzi F., Barbanera M., Analisi del ciclo di vita del pellet da SRF attraverso misure dirette dei consumi energetici. Proceedings of the $61^{\circ}$ ATI National Congress - Perugia 12-15 September 2006.

Cosentino S.L., Copani V., D'Agosta G.M., Sanzone E., Mantineo M., First results on evaluation of Arundo don$a x \mathrm{~L}$. clones collected in Southern Italy. Industrial Crops and Products, 2006, 23, 212-222.

European Biofuel Technology Platform, European Biofuel Technology Platform: Strategic Research Agenda and Strategy Deployment Document, CPL Scientific Publishing Services Ltd., UK (2008).

Final report of PRIN2007 research project on "Production and energy transformation of herbaceous biomasses irrigated with wastewater" funded by the Ministry of Instruction, University and Research (MIUR) - Year 2007, prot. 2007R5XS35.

Hanegraff M.C., Biewinga E.E., van Der Bijl, G., Assessing the ecological and economic suistainalibilty of energy crops. Biomass and Bioenergy, 1998, vol. 15 n. 4/5, 345355.

Heller M.C., Keoleian G.A., Volk T.A., Life cycle assessment of a willow bioenergy cropping system. Biomass and Bioenergy, 2003, 25, 147-165.

Iriarte A., Rieradevall J., Gabarrell X., Life cycle assessment of sunflower and rapeseed as energy crops under Chilean conditions. Journal of Cleaner Production, 2010, $18,336.345$.

Jungmeier G., Spitzer J., Greenhouse gas emissions of bioenergy from agriculture compared to fossil energy for heat and electricity supply. Nutrient Cycling in Agroecosystems, 2001, 60, 267-273.

Klöpffer W., The role of SETAC in the development of LCA. International Journal of Life Cycle Assessment, 2006, 11, 116-122.

Lewandowski I., Heinz A., Delayed harvest of miscanthus-influences on biomass quantity and quality and environmental impacts of energy production. European Journal of Agronomy, 2003, 19, 45-63.

Mantineo M., D’Agosta G.M., Copani V., Patanè C., Cosentino S.L., Biomass yield and energy balance of three perennial crops for energy use in the semi-arid 
Mediterranean environment. Field Crops Research, 2009, 114, 204-213.

Muñoz I., Gómez M., Fernández-Alba A.R., Life Cycle Assessment of biomass production in a Mediterranean greenhouse using different water sources: Groundwater, treated wastewater and desalinated seawater. Agricultural Systems, 2010, 103, 1-9.

PRé Consultants, 2008a. Introduction to LCA with SimaPro 7. Amersfoort, The Netherlands; http://www.pre.nl.

PRé Consultants, 2008b. SimaPro Database Manual Methods library. The Netherlands; http://www.pre.nl.

Recchia L., Cini E., Corsi S., Multicriteria analysis to evaluate the energetic reuse of riparian vegetation. Applied Energy, 2010, 87, 310-319.

Russell A., Ekvall T., Baumann H., Life cycle assessment introduction and overview. Editorial, Journal of Cleaner Production, 2005, 13: 1207-1210.

Scipioni A., Mazzi A., Niero M., Boatto T., LCA to choose among alternative design solutions: The case study of a new Italian incineration line. Waste Management, 2009, 29, 2462-2474.

UNI. 1997. UNI EN ISO 14040. Environmental Management - Life Cycle Assessment - Principles and Framework. 1997.

UNI. 1998. UNI EN ISO 14041. Environmental management - Life cycle assessment - Goal and scope definition and inventory analysis. 1998.

UNI. 2000a. UNI EN ISO 14042. Environmental management - Life cycle assessment - Life cycle impact assessment. 2000.

UNI. 2000b. UNI EN ISO 14043. Environmental management - Life cycle assessment - Life cycle interpretation. 2000 .

UNI. 2006a. UNI EN ISO 14040. Environmental management - Life cycle assessment - Principles and framework. 2006
UNI. 2006b. UNI EN ISO 14044. Environmental management - Life cycle assessment - Requirements and guidelines. 2006.

\section{SUMMARY}

In this study the Life Cycle Assessment (LCA) of the Arundo donax production process for energy purpose is proposed. The cultivation of this type of herbaceous biomass, irrigated with urban wastewater, was carried out in an experimental field, sited in eastern Sicily (Italy). The analysis by LCA makes it possible, among other things, to evaluate the potential environmental impacts related to each phase of the process. In this study a sensitivity analysis of the LCA results were carried out by varying the process stages. Furthermore the incidence of each process stage on the damage categories by varying the cultivation-cycle length was evaluated. The stages constituting the Arundo donax production process, considered in this assessment, regard seedling production, agronomic practices, irrigation, and transport to boiler. The functional unit used in the analyses was 1 ton of biomass and crop productivity values were derived from literature. The analyses allowed to identify the most significant stages of the Arundo donax production process related to the experimental field. In detail, this study highlights that seedling production and irrigation stages contributed most of all to the overall environmental burden, whereas agronomic practices stage showed a minor influence on the process.

Keywords: Arundo donax, environmental performance, damage categories. 